Hydrol. Earth Syst. Sci., 14, 667-674, 2010

www.hydrol-earth-syst-sci.net/14/667/2010/

(C) Author(s) 2010. This work is distributed under

the Creative Commons Attribution 3.0 License.

\title{
Evidence for double diffusion in temperate meromictic lakes
}

\author{
C. von Rohden ${ }^{1}$, B. Boehrer ${ }^{2}$, and J. Ilmberger ${ }^{1}$ \\ ${ }^{1}$ Institute of Environmental Physics, University of Heidelberg, Heidelberg, Germany \\ ${ }^{2}$ UFZ-Helmholtz Centre for Environmental Research, Magdeburg, Germany
}

Received: 26 November 2009 - Published in Hydrol. Earth Syst. Sci. Discuss.: 7 December 2009

Revised: 18 March 2010 - Accepted: 31 March 2010 - Published: 13 April 2010

\begin{abstract}
We present CTD-measurements from two shallow meromictic mining lakes. The lakes, which differ in size and depth, show completely different seasonal mixing patterns in their mixolimnia. However, the measurements document the occurrence of similar seasonal convective mixing in discrete layers within their monimolimnia. This mixing is induced by double diffusion and can be identified by the characteristic step-like structure of the temperature and electrical conductivity profiles. The steps develop in the upper part of the monimolimnion, when in autumn cooling mixolimnion temperatures have dropped below temperatures of the underlying monimolimnion. The density gradient across the chemocline due to solutes overcompensates the destabilizing temperature gradient, and moreover, keeps the vertical transport close to molecular level. In conclusion, preconditions for double diffusive effects are given on a seasonal basis. At in general high local stabilities $N^{2}$ in the monimolimnia of $10^{-4}-10^{-2} \mathrm{~s}^{-2}$, the stability ratio $R_{\rho}$ was in the range of $1-20$. This quantitatively indicates that double diffusion can become visible. Between 1 and 6 sequent steps, with sizes between $1 \mathrm{dm}$ and $1 \mathrm{~m}$, were visually identified in the CTDprofiles. In the lower monimolimnion of the deeper lake, the steps systematically emerge at a time delay of more than half a year, which matches with the progression of the mixolimnetic temperature changes into the monimolimnion. In none of the lakes, the chemocline interface is degraded by these processes. However, double diffusive convection is essential for the redistribution of solutes in the inner parts of the monimolimnion at longer time scales, which is crucial for the assessment of the ecologic development of such lakes.
\end{abstract}

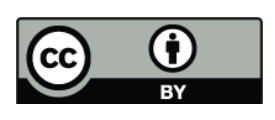

Correspondence to: C. von Rohden (christoph.vonrohden@iup.uniheidelberg.de)

\section{Introduction}

The phenomenon of double diffusive convection has been discussed in detail in numerous observational, laboratory, and theoretical studies (e.g. Turner, 1973; Kelley, 2003; Schmitt, 1994). Field observations have been described at first in the ocean at mid and low latitudes where the salt finger regime dominates, and to lesser extent to high latitudes where the diffusive regime occurs. Soon, double diffusion and the step-like structure of the associated salt and temperature profiles were also described in lakes (Hoare, 1966; Newman, 1976). The precondition for the occurrence of diffusive layering in lakes are a density stratified water column stabilized by dissolved or suspended matter and, at the same time, a destabilizing temperature gradient, in the respective depth regions. These conditions often prevail in meromictic lakes.

Meromixis is a well known phenomenon, also occurring in lakes located in regions in a temperate climate (Boehrer and Schultze, 2008). A strong stable density stratification due to chemical gradients in and below the chemocline separates the oxic mixolimnion from the mostly anoxic monimolimnion. Density gradients restrict vertical exchange, especially in the chemocline, where vertical transport of heat and substances can drop to the molecular level (von Rohden et al., 2009).

The destabilizing monimolimnetic temperature profile is often supported by geothermal heating from the sediments, with temperatures well above the point of maximum density. Although it was shown in a few - also natural - lakes that such a configuration of heat and salt stratification in the deep water should be sensitive to double diffusive processes, e.g. in Lake Lugano (Wüest et al., 1992) or in the strongly meromictic Brenda Mines pit lake (Stevens and Lawrence, 1998), few reports on the explicit appearance of characteristic double-diffusive steps or staircases as a result of local convective mixing for lakes in temperate climates exist so far. Sánchez et al. (2007) present microstructure profiles of temperature and salinity and particle concentration data from

Published by Copernicus Publications on behalf of the European Geosciences Union. 


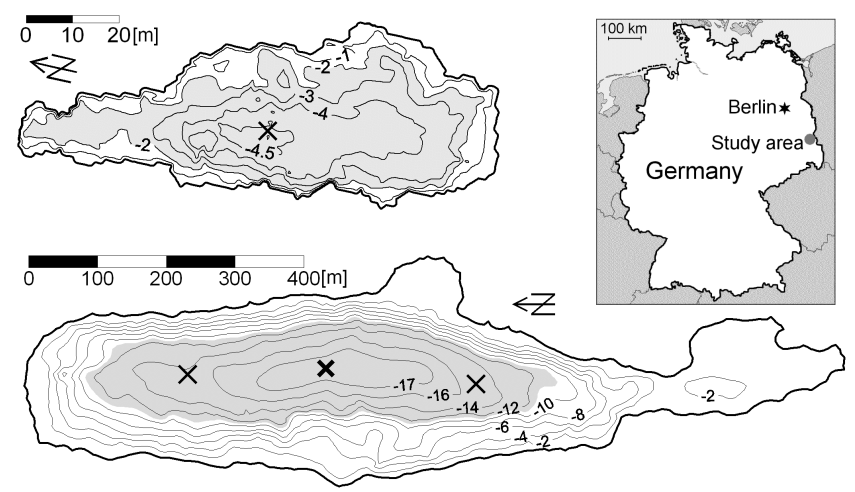

Fig. 1. Bathymetric maps of Lake Waldsee and Lake Moritzteich. The grey shaded areas denote the surfaces of the monimolimnia. Measurements took place at the sites marked by crosses.

the $\sim 1 \mathrm{~m}$ thick bottom water body in the $\sim 35 \mathrm{~m}$ deep carstic Lake Banyoles in Spain, where a triple diffusive staircase was sustained. España et al. (2009) give another example of step-like structures in the bottom-heated monimolimnion of a mining lake in Spain. The temperature and conductivity data support the assumption of the authors that this can be the result of double diffusive convection.

In this study, we refer to the monimolimnia of two shallow meromictic mining lakes. Boehrer et al. (2009) report on a first observation of an overturn comprising the whole monimolimnion without destruction of the chemocline, observed 2006 in one of these lakes (Lake Waldsee). We report on extended observations (2006-2008) from the same lake and a neighboring lake. These examples show that the decline of the mixolimnion temperatures during the cold mixing season facilitates the condition for convective mixing in the monimolimnion due to double diffusion - at least temporarily. As a consequence, parts of the inner monimolimnia are mixed seasonally at a depth (gradient) dependent pattern. We propose that double diffusive mixing could lead to substantial seasonal mixing in stratified monimolimnia of temperate meromictic lakes.

\section{Site description and methods}

The study sites Lake Waldsee $\left(51^{\circ} 37^{\prime} 14.1^{\prime \prime} \mathrm{N}\right.$, $\left.14^{\circ} 34^{\prime} 16.7^{\prime \prime} \mathrm{E}\right)$, and Lake Moritzteich $\left(51^{\circ} 35^{\prime} 20^{\prime \prime} \mathrm{N}\right.$, $\left.14^{\circ} 34^{\prime} 30^{\prime \prime} \mathrm{E}\right)$ are located in the Lusatian lignite mining district in Germany (Fig. 1). After cessation of lignite mining several decades ago, the lakes have filled mainly by groundwater inflow. Surface areas, volumes and maximum depths are $2387 \mathrm{~m}^{2}$ and $165700 \mathrm{~m}^{2}, 6542 \mathrm{~m}^{3}$ and $1.26 \times 10^{6} \mathrm{~m}^{3}, 4.7 \mathrm{~m}$ and $17.4 \mathrm{~m}$, respectively. The surfaces of the monimolimnia constitute large parts of the lake surfaces due to rather steep side walls of lake basins (Fig. 1).

Measurements were done monthly by lowering an automatic CTD-probe (Idronaut Ocean Seven 319, Brugherio,

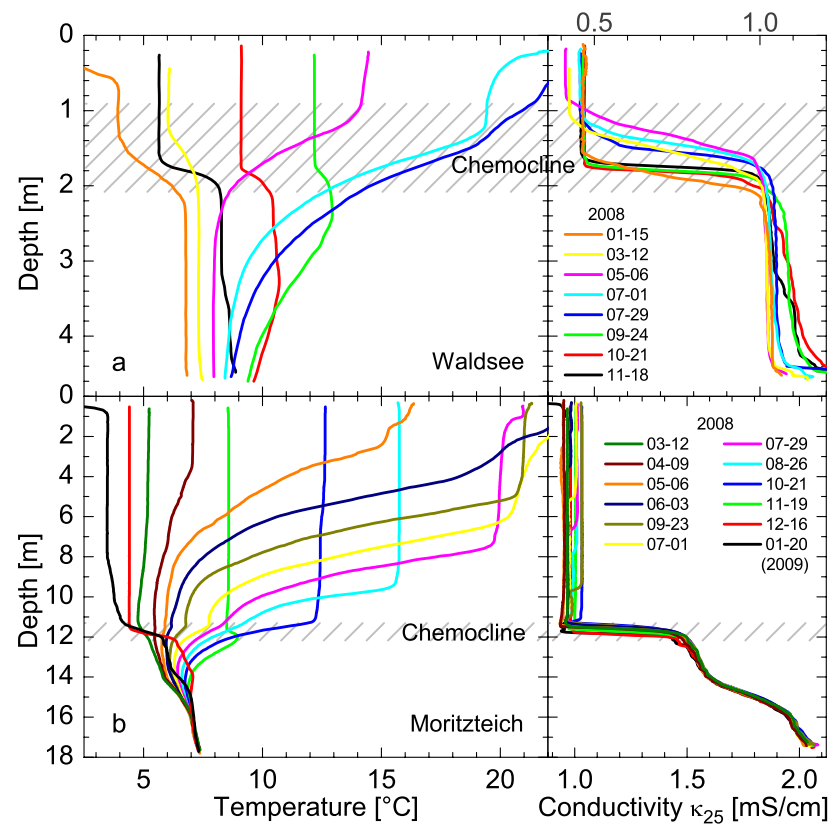

Fig. 2. Selected profiles of temperature and electrical conductivity (corrected to $25^{\circ} \mathrm{C}$ ) of (a) Lake Waldsee and (b) Lake Moritzteich, illustrating typical seasonal cycles.

Italy). The accuracy of the conductivity and temperature sensors are $3 \mu \mathrm{S} / \mathrm{cm}$ and $0.003{ }^{\circ} \mathrm{C}$, respectively. The resolution is $0.1 \mu \mathrm{S} / \mathrm{cm}$ and $0.0007^{\circ} \mathrm{C}$, respectively. The resolution of the pressure sensor is $0.02 \mathrm{dbar}(\sim 2 \mathrm{~cm})$. The sampling frequency is $5 \mathrm{~Hz}$, the response time of both sensors is $\sim 50 \mathrm{~ms}$ and hence 4 times faster than the sampling. The design of the cylindrically shaped conductivity sensor involves averaging over a vertical distance of $\sim 4.5 \mathrm{~cm}$. The position of the temperature sensor tip with respect to depth approximately corresponds to the center of the conductivity cell. The probe was lowered by hand at a speed of $\sim 10 \mathrm{~cm} / \mathrm{s}$.

Figure 2 displays an overview of CTD - profiles exemplary for the year 2008. They stand for typical seasonal cycles of temperature and electrical conductivity documenting the meromixis. Each of the graphs is an average of 3-6 single CTD-profiles, which were consecutively taken within 10-20 min at each site. To account for variations of the water level in the lake, the depth scale in meters in all figures refers to a fixed reference.

During the warm period, heat slowly proceeds through the chemocline into the monimolimnion towards the lake bottom of the shallow Lake Waldsee (Fig. 2a). Starting with the autumnal cooling, temperature inversions form within and below the chemocline. In winter, we find inverse temperature profiles stabilized by the strong gradient of solutes. Although the lake is shallow and the chemocline is located at depths between only 1 and $2 \mathrm{~m}$, the chemocline is preserved throughout the years. The persistence of the meromixis is supported by the wind protected location within a forest, 
chemical reactions affecting density gradients at the chemocline (see below), and probably the interaction with groundwater. The variation of the chemocline depth with an amplitude of $\sim 1 \mathrm{~m}$ follows a clear seasonal cycle. Von Rohden et al. (2009) discuss this as a result of convective mixing in the mixolimnion. Convective mixing of the upper layer is strongest during summer when nocturnal cooling removes the heat of the preceding daytime through the surface. This drives a convection which reaches the (shallow) chemocline. Therefore the depth of the chemocline gradually increases during summer (chemocline erosion). In the cool season, mixing in the surface layer is weaker (wind speed $2 \mathrm{~m}$ above the lake surface $\sim 0.5 \mathrm{~m} / \mathrm{s}$ on average, virtually not exceeding $2 \mathrm{~m} / \mathrm{s}$ ), and the chemocline gradually moves upwards, presumably due to groundwater inflow.

Figure $2 \mathrm{~b}$ illustrates the situation in the larger Lake Moritzteich. The upper $\sim 11 \mathrm{~m}$ of the water column undergo the "usual" thermal cycle of temperate lakes with a warm epilimnion and a cooler hypolimnion in summer and a homothermal mixolimnion during the cool season. During the warm season starting in April, heat slowly enters the upper monimolimnion (similar to Lake Waldsee). This heating still continues while autumnal cooling already affects the mixolimnion. After the formation of local temperature maxima (e.g., on 19 November at $\sim 12 \mathrm{~m}$ ), an inverse temperature profile establishes with gradients of $2-3^{\circ} \mathrm{C} / \mathrm{m}$ between the mixed $\sim 4^{\circ} \mathrm{C}$ mixolimnion and the warmer monimolimnion. Heat diffuses out of the monimolimnion along these gradients. In general, the seasonal temperature signal at the top of the chemocline intrudes to a depth of about $16 \mathrm{~m}$, i.e. at least $4 \mathrm{~m}$ into the monimolimnion. The monimolimnion temperatures follow the mixolimnion signal with a depth dependent delay. For example in the profile of 16 December 2008, the temperature has a local maximum at $\sim 14 \mathrm{~m}$ while the mixolimnion is cooler, close to $4^{\circ} \mathrm{C}$. Towards the bottom, the temperature remains inversely stratified with much less variation, ending at a virtually constant value of $\sim 7.3^{\circ} \mathrm{C}$. This indicates a continuous heat flux from the sediments. With respect to electrical conductivity, we find a subdivision of the monimolimnion into two layers: The "upper" monimolimnion extends from the chemocline to $\sim 14 \mathrm{~m}$ depth. It is separated by a density step from the "lower" monimolimnion extending from $\sim 15.8 \mathrm{~m}$ to the bottom. This structure as a whole has persisted for several years and has shown only little variation.

While the seasonal mixing in the water bodies above the chemoclines is quite different between the lakes, their behaviour regarding the meromixis is similar. Seasonal temperature changes at the top of the chemocline proceed faster and deeper into the monimolimnion than variations of conductivity. This indicates that the effective diffusivities of heat and solutes are different. Hence, vertical transport must to a large extent be at a level close to the molecular diffusion, especially within the chemocline.
The vertical density gradients are mainly caused by gradients of dissolved iron and the carbonate system. Ferrous iron $\left(\mathrm{Fe}^{\mathrm{II}}\right)$ which is transported out of the anoxic monimolimnia by diffusion is oxidized in the lower hypolimnion. As particulate ferric iron $\left(\mathrm{Fe}^{\mathrm{III}}\right)$ it settles back into the monimolimnion, where it eventually redissolves. This chemical cycle results in the conservation of distinct chemoclines and implies an evanescent effective transport of the density regulating iron, sustaining the chemical and therefore the stable density stratification across the chemocline. These geochemical processes are discussed by means of lake Waldsee in Boehrer et al., (2009). The temporal variation of the overall electrical conductivity $\left(\kappa_{25}\right)$ in the mixolimnion and monimolimnion of Lake Waldsee by about $10 \%$ (Fig. 2a) results from the seasonality of transport pattern interacting with the (bio)chemical redox cycle.

The interplay of permanent stratification and annual temperature cycle delivers the condition required for double diffusion: Due to the high stability across the chemocline the effective transport is limited to the molecular level. Below the chemocline, where the salt gradients are much smaller, the stratification can become unstable when inverse temperature gradients increase due to the ongoing diffusive upward heat loss and outbalance haline density stratification. This can initiate convection at localized depths.

As discussed above, the salt composition in the studied mining lakes is different from that in natural lakes. Furthermore, the relative composition regarding iron and bicarbonate differs significantly between mixolimnion and monimolimnion. We therefore developed specific formulas to calculate water density from measured electrical conductivity and temperature, since standard formulas (e.g. Chen and Millero, 1986) did not apply (e.g., Hamblin et al., 1999). For Lake Waldsee the procedure was explained in detail in Boehrer et al. (2009). There, also chemical data at different depths were presented. Laboratory measurements on the temperature dependence of the electrical conductivity for epilimnion and monimolimnion samples from both lakes were performed. From the linear regression to the data from $1.5^{\circ} \mathrm{C}$ to $30^{\circ} \mathrm{C}$ the electrical conductivity for the chosen reference temperature of $25^{\circ} \mathrm{C}$ could be evaluated:

$\kappa_{25}=\frac{C(T)}{\alpha_{25}\left(T-25^{\circ} C\right)+1}$,

where $\alpha_{25}=1 /(25+n / m)$, and $\mathrm{n}, \mathrm{m}$ are the respective regression coefficients (Boehrer and Schultze, 2008). The specific temperature dependence of the density in the mixolimnion and monimolimnion water $\left(\rho_{\text {mixo }}\right.$ and $\left.\rho_{\text {moni }}\right)$ was determined by measurements using a densitometer (DSA 5000, PAAR, Austria) with a relative accuracy of $2 \times 10^{-6}$ and fitting these data by a fourth-order polynomial.

Based on the CTD-casts in the field, the density profiles were then calculated by

$$
\rho\left(T, \kappa_{25}\right)=\rho_{\text {mixo }}(T)+\left[\rho_{\text {moni }}(T)-\rho_{\text {mixo }}(T)\right] \cdot \frac{\left(\kappa_{25}-\kappa_{\text {mixo }}\right)}{\left(\kappa_{\text {moni }}-\kappa_{\text {mixo }}\right)},
$$




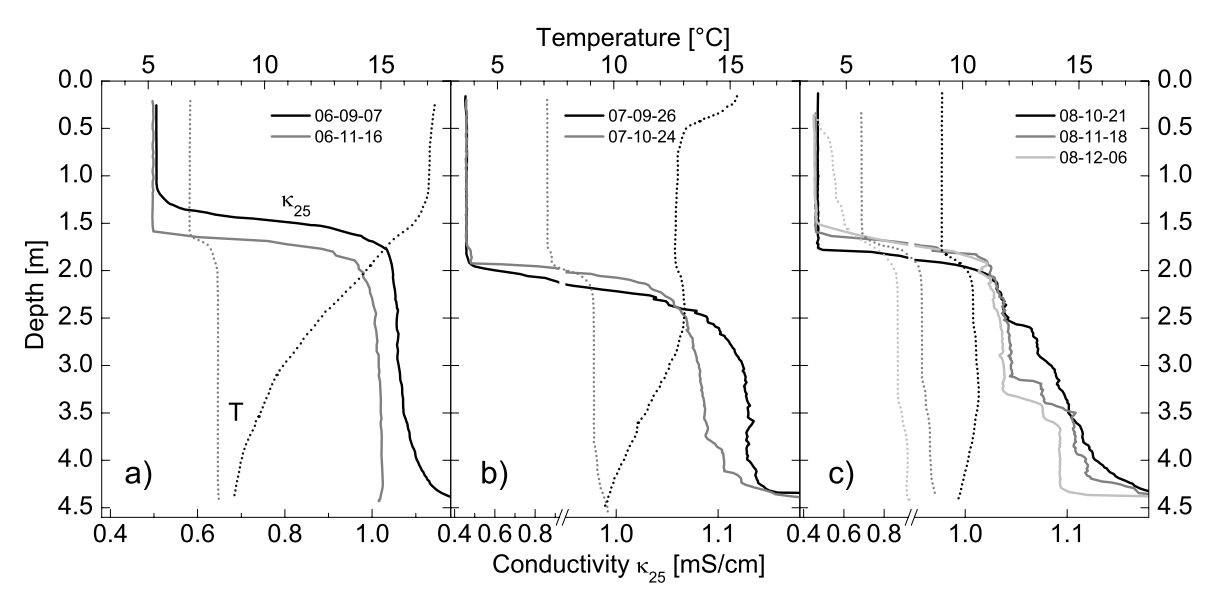

Fig. 3. Exemplary CTD-profiles at Lake Waldsee from three different years documenting variable shaping of double diffusive mixing (formation of steps) after onset of mixolimnion cooling: (a) (2006) complete overturn of the monimolimnion (= one step), (b) (2007) steps close to the bottom, (c) (2008) steps within the monimolimnion, migrating downwards with time. In panels a) and b) the preceding overall stable situations are plotted for comparison. Note the axis breaks for conductivity in panels (b) and (c).

where $\kappa_{\text {mixo }}$ and $\kappa_{\text {moni }}$ are the values of $\kappa_{25}$ in the mixolimnion and monimolimnion samples of both lakes, considered as representative for the study period, and assuming that the transition in the chemocline is proportional to the conductivity $\kappa_{25}$.

Based on this density we derived the local stability $N^{2}$ (in $1 / \mathrm{s}^{2}$ ) and the stability ratio $R_{\rho}$ :

$N^{2}=-\frac{g}{\rho} \frac{\partial \rho}{\partial z}=-\frac{g}{\rho}\left(\frac{\partial \rho}{\partial T} \frac{\partial T}{\partial z}+\frac{\partial \rho}{\partial \kappa_{25}} \frac{\partial \kappa_{25}}{\partial z}\right)$,

$R_{\rho}=-\left(\frac{\partial \rho}{\partial \kappa_{25}} \frac{\partial \kappa_{25}}{\partial z}\right) /\left(\frac{\partial \rho}{\partial T} \frac{\partial T}{\partial z}\right)$

$N^{2}$ quantifies the local density stratification. $R_{\rho}$ compares the stabilizing salinity gradient with the destabilizing temperature gradient and therefore highlights the sensitivity to double diffusive effects.

The observed step sizes in the CTD-profiles were compared to the theoretical estimation after the semi-empirical approach of Kelley (1984) (in m):

$H_{\text {Kelley }}=\left[\frac{v}{D_{T}} 0.25 \times 10^{9} R_{\rho}^{1.1}\left(R_{\rho}-1\right)\right]^{1 / 4} \sqrt{\frac{D_{T}}{N}}$,

with $v$ the kinematic viscosity of water $\left(8.9 \times 10^{-7} \mathrm{~m}^{2} / \mathrm{s}\right)$ and $D_{T}$ the molecular diffusion coefficient of heat $(1.4 \times$ $\left.10^{-7} \mathrm{~m}^{2} / \mathrm{s}\right)$. $H_{\text {Kelley }}$ considers both stabilizing and destabilizing components by parameterization with $R_{\rho}$, calculated from measurements with Eqs. 1-4.

\section{Evidence for double diffusive steps}

In the following we discuss the CTD-measurements with respect to the formation of step-like structures in the moni- molimnia of both studied lakes, which are considered to be the result of double diffusion.

\subsection{Lake Waldsee}

Figure 3 exemplarily shows CTD-profiles from the last thirds of the years 2006, 2007 and 2008. They document a variety of step formations by double diffusion with respect to depth, size, and time. Partial convective mixing was initiated when destabilizing temperature gradients arose in the chemocline region after onset of the cool season. The profile from November 2006 (Fig. 3a) could be considered as one final step resulting from continuous downward mixing from the chemocline to the bottom over a time period of several weeks. This event implies complete mixing of the monimolimnion without destroying the chemocline. We included these profiles, which already have been described in Boehrer et al. (2009), to emphasize the variable shaping of the double diffusive steps. Figures $3 \mathrm{~b}$ and $\mathrm{c}$ indicate several steps at different depths with sizes of about one to several decimeters. Although the measurements at intervals of $\sim 1$ month are snapshots, a slow downwards migration of some of the steps from the three profiles in autumn 2008 (Fig. 3c) could be alleged.

In Fig. 4a, the situation before and after onset of step formation in 2008 is shown. Panels (b) and (c) display the respective local stability $N^{2}$ and the stability ratio $R_{\rho}$. The vertical gradients for calculation of $N^{2}$ and $R_{\rho}$ were derived as the slopes of linear fits running over 5 consecutive data points $(\sim 10 \mathrm{~cm})$. Structures larger than this scale can be regarded as real, whereas smaller scales cannot be distinguished from statistical fluctuations of the measurements. In the earlier profile (24 September), $R_{\rho}$ values between $\sim 2$ and 8 were present at a depth around $\sim 2 \mathrm{~m}$, i.e. just below 


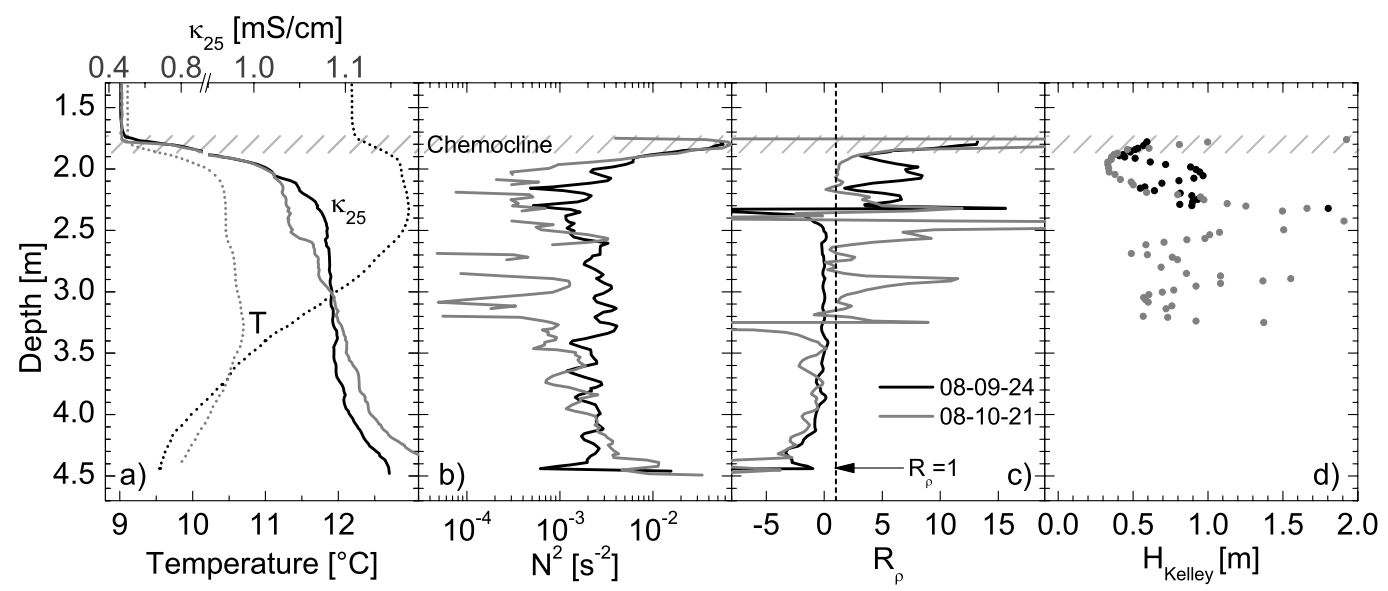

Fig. 4. (a) profiles of Temperatures and electrical conductivity at $25^{\circ} \mathrm{C}$, (b) Local stability $N^{2}$, (c) stability ratio $R_{\rho}$, and (d) calculated size of potential double diffusive steps in a situation before (24 September 2008) and after (21 October 2008) the onset of convection in the monimolimnion of Lake Waldsee (a).

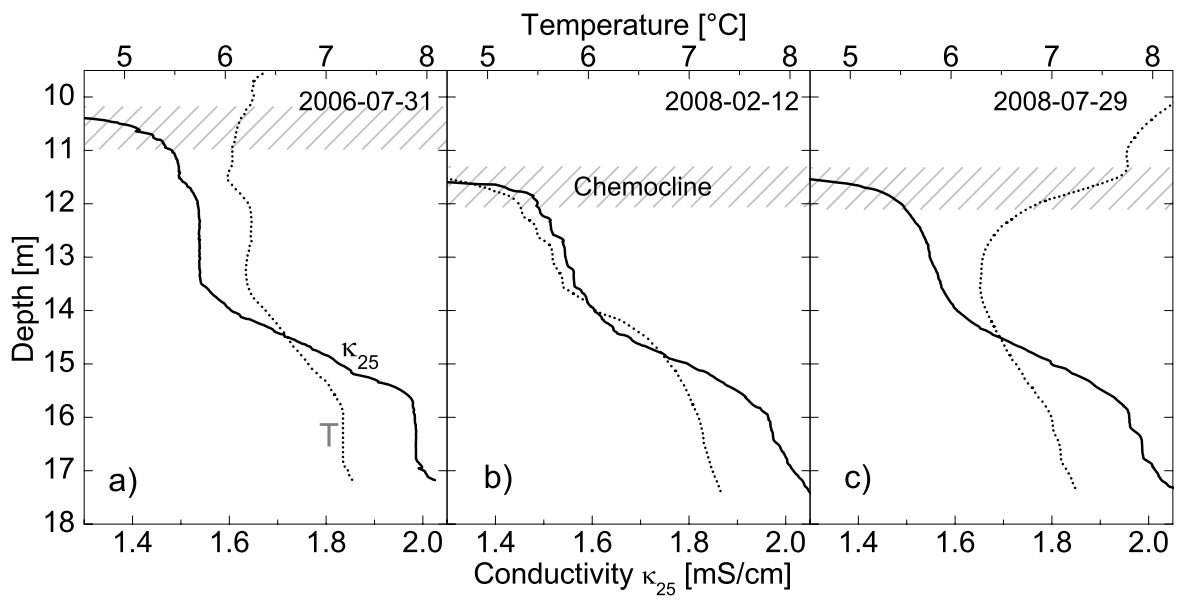

Fig. 5. CTD - profiles at Lake Moritzteich from two different years documenting variable shaping of double diffusive mixing (formation of steps): (a) (2006) two steps in the upper part of the monimolimnion, one step near the bottom, (b) (2008, winter) several steps in the upper part, no clear structure near the bottom, (c) (2008, summer) steps in the upper part disappeared, step formation near the bottom.

the chemocline, whereas the deeper monimolimnion was still stabilized by both conductivity and temperature (negative $\left.R_{\rho}\right)$. The $R_{\rho}$-variation from 21 October reflects the existing steps in the double diffusive depth section between 2.5 and $3.3 \mathrm{~m}$, whereas the lowermost part of the monimolimnion is still stable. The estimation of the potential step sizes after Kelley (1984) yields $\sim 0.3-1 \mathrm{~m}$ in the relevant depth section of 1.9-2.3 m. Although larger, they are of the same order of magnitude as the observed steps in the deeper section, taking into account the transient nature of the structures.

\subsection{Lake Moritzteich}

In Fig. 5, three examples of double diffusive steps in Lake Moritzteich are presented. Panel (a) suggests two steps in the "upper" monimolimnion layer. They are "left over" from the last period with diffusive heat loss into the mixolimnion by strong inverse temperature gradients in the preceding winter, and extend over $\sim 0.5$ and $\sim 1.5 \mathrm{~m}$. In the lower layer, we find one step of $\sim 1 \mathrm{~m}$ thickness. Panels (b) and (c) demonstrate well the seasonality and the depth and time dependent occurrence of the step formation, respectively: In the 'upper' monimolimnion, staircases with one to six clearly identifiable steps were observed during the cool periods in different years. At least four are present in the plotted example from 12 February 2008 with sizes in the range from 30 to $50 \mathrm{~cm}$, while much less structure is visible in the "lower" part. However, about half a year later, the steps in the upper monimolimnion disappeared, whereas clear steps of typically $0.5 \mathrm{~m}$ height have formed in the layer near the bottom (Fig. 5c, 29 August 2008). 


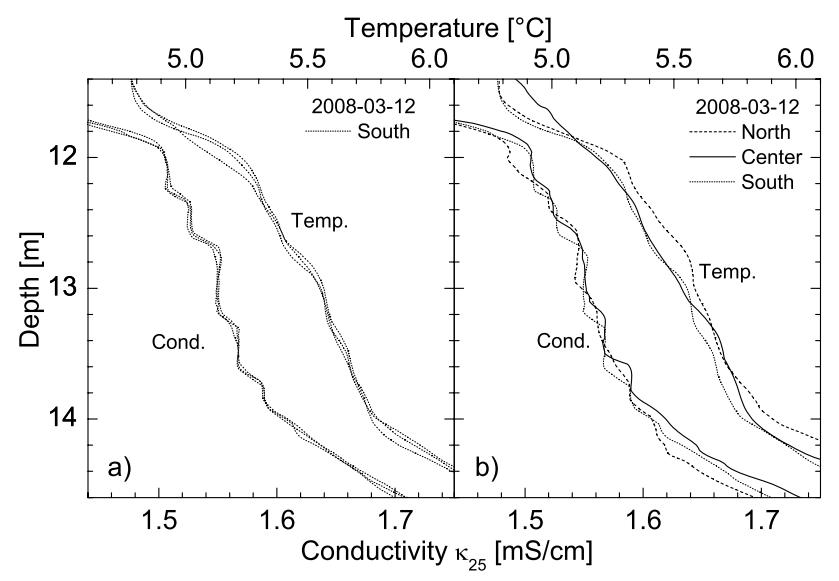

Fig. 6. CTD-profiles from three different sites at Lake Moritzteich (section of double diffusive zone in the upper part of the monimolimnion) Panel (a): Consecutively taken profiles to verify the reproducibility of single measurements. Panel (b): Profiles from three different measurement sites to illustrate horizontal homogeneity.

The considerations involve the assumption of horizontal homogeneity of the measured quantities. This assumption was verified several times for both lakes by CTD-casts from different sites at the same date. For Lake Moritzteich, profile sections from the double diffusive zone in the "upper" monimolimnion on 12 March 2008 are plotted in Fig. 6. Three to four single profiles were measured consecutively at each of the three sites (crosses in Fig. 1). Figure 6a illustrates the reproducibility for a set of profiles, exemplarily from one site. Figure $6 \mathrm{~b}$ essentially confirms horizontal homogeneity of the observed structures. Although systematic vertical displacements of a few decimeter between the profiles from different sites are visible, possibly caused by internal waves with low amplitudes, the electrical conductivities of steps coincide.

The observations suggest that the steps in the deeper layer arise systematically with a certain time lag. This delay should be related to the speed at which the thermal (cooling) signal from the upper layer proceeds downwards. With the permanently stably stratified intermediate layer extending from $\sim 14.0 \mathrm{~m}$ to $\sim 15.5 \mathrm{~m}(\Delta z \sim 1.5 \mathrm{~m})$ (Fig. 5), the time scale for the propagation of the signal can estimated to be $\Delta \tau=\Delta z^{2} / D_{T} \cong 200$ days, with $D_{T}$ the coefficient of molecular diffusion of heat. This explains the observed temporal pattern and suggests that the effective diffusivity in this depth section must be constrained to values close to the molecular level. In summary, cooling at the chemocline in late autumn and winter drives double diffusive convection in the upper half of the monimolimnion until the following late spring, and subsequently in the deepest part with a delay of more than half a year. Here, even in late autumn 2008, convective steps could be observed, while the following cooling period has already started.
From density, we derived local stability $N^{2}$ and stability ratio $R_{\rho}$, smoothed over 9 data points $(\sim 18 \mathrm{~cm})$. Figures $7 \mathrm{a}$ and $\mathrm{b}$ exemplarily show the situations in February and July 2008 (Figs. 5b and c). Despite the considerable variation, a tendency towards $R_{\rho}<30$ approaching the critical value of $1 \mathrm{can}$ be quoted in February for both depth regions in the "upper" and "lower" monimolimnion, indicating the potential for double diffusive effects. Certainly, $R_{\rho}$ in the 'upper' monimolimnion is already determined by an existing staircase. In August, the upper part of the profile was smooth and stably stratified resulting in negative $R_{\rho}$, while the bottom part again reflected a double diffusive situation with existing steps.

Similar to Lake Waldsee the thicknesses of the observed mixed layers are highly variable, though no complete mixing was observed neither of the whole monimolimnion nor within the different layers. Recalculation with the approach of Kelley (1984) yields a range of $\sim 0.5-2 \mathrm{~m}$ (Fig. 7c). As in Lake Waldsee, this seems to be up to several times larger than the observations. However, this is not necessarily in contradiction, as calculated step sizes are prognostic estimates, originally based on oceanic conditions with much less temporal (temperature) variability at the boundaries of the relevant double diffusive zones. Changes of the boundary conditions at the chemoclines with comparatively large amplitudes may explain this variability in the studied lakes and even may hamper the steps from full development. Nevertheless, the steps can reach sizes in the same range as reported from other lakes with rather small background gradients, e.g., Lake Nyos (Schmid et al., 2004). The overall two-step structure in the monimolimnion of Lake Moritzteich (Fig. 2b) can be considered as the long-term result of the temporally and spatially separate occurrence of double diffusive convection.

In both lakes the interfaces are sharper for conductivity than for temperature. This is not an instrumental effect. An "in-situ"-smoothing is expected to be produced by averaging of the $\sim 4.5 \mathrm{~cm}$ long conductivity cell but not by the temperature sensor. However, the observations are opposite to this. The profiles seem plausible, as initially sharp edges smooth faster for temperature than for conductivity due to higher molecular heat diffusivity. Though, this implies that the local convection which causes the steps occurs rather occasionally than continuously, giving the chance for diffusive interface smoothing at different rates.

\section{Conclusions}

The observations show that convective mixing triggered by double diffusive processes in monimolimnia of meromictic lakes can be part of the seasonal mixing regime. A precondition is that the mixolimnetic temperature cycle above the monimolimnion is strong enough to initiate destabilizing gradients which migrate sufficiently deep into the monimolimnion. Such conditions are provided in shallow 


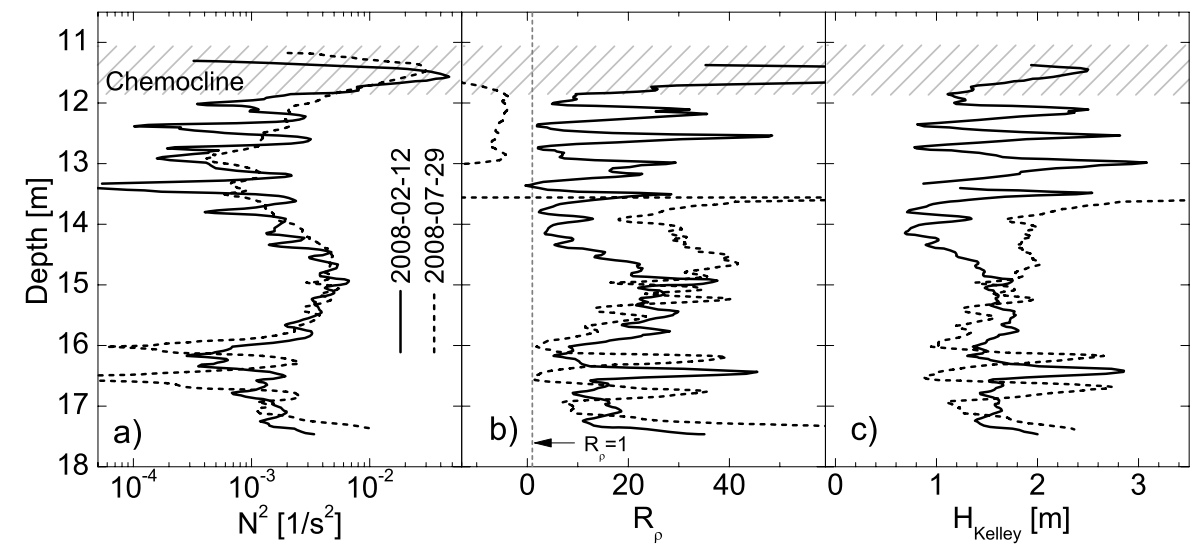

Fig. 7. (a) Local stability $N^{2}$, (b) stability ratio $R_{\rho}$, (c) calculated size of potential double diffusive steps for two situations in February and August 2008 in the monimolimnion of Lake Moritzteich.

meromicitc lakes in temperate climates. On the one hand, the occurrence of double diffusion confirms that the exchange between monimolimnion and mixolimnion and within the monimolimnion must in general be as low as molecular. As a result, double diffusion follows the seasonal forcing with a depth dependent time lag. On the other hand, monimolimnia can in parts undergo convective mixing, enhancing effective vertical fluxes of heat and solutes. However, the stability of the stratification within the chemocline, i.e. the meromixis itself, is not necessarily degraded by these processes or even may periodically be enhanced as the chemocline gets sharpened from below.

Generally the precondition for double diffusive mixing, i.e., seasonal surface cooling, is the same as in other lakes, e.g., Lake Nyos (Schmid et al., 2004). A heat flux from the sediments favours double diffusion but is not a precondition. However, the magnitude of the forcing, i.e., the extent of the seasonal temperature variation above the monimolimnion as well as the strength of the stabilizing salt and destabilizing temperature gradients are rather high in the presented examples. The water column is in parts sensitive to double diffusive mixing, although the overall stability in the respective depth regions is high at $N^{2} \sim 10^{-3} \mathrm{~s}^{-2}$ (Figs. 4 and 7). The number and thicknesses of double diffusive steps should be very sensitive to the continuously changing gradients, which may explain the relative discontinuity of the texturing at the time scale of the observations.

These mechanisms could be widespread among meromictic lakes in temperate climates, as many of them might meet the required preconditions. This should especially be important for existing and future pit lakes from open-cast mining, because such lakes are above-average prone to meromixis. Finer resolution of measurements both in space and time will allow investigating the dynamics of double diffusive processes much more in detail, e.g. the time scale of formation and persistence of steps or the relation of step size to am- bient gradients in temperature and salinity. High resolution thermistor chain records and microstructure measurements should be implemented in more detailed investigations.

Acknowledgements. This work was financially supported by the German Research Foundation (DFG). Thanks to Uwe Kiwel (Helmholtz Centre for Environmental Research UFZ, Magdeburg) for support in the field.

Edited by: A. D. Reeves

\section{References}

Boehrer, B. and Schultze, M.: Stratification of Lakes, Rev. Geophys., 46, 1-27, 2008.

Boehrer, B., Dietz, S., von Rohden, C., Kiwel, U., Jöhnk, K. D., Naujoks, S., Ilmberger, J., and Lessmann, D.: Double-diffusive deep water circulation in an iron-meromictic lake, Geochem. Geophy. Geosy., 10, 1-7, doi:10.1029/2009GC002389, 2009.

Chen, C.-T. A. and Millero, F. J.: Precise thermodynamic properties for natural waters covering only the limnological range, Limnol. Oceanogr., 31, 657-662, 1986.

España, J. S., Pamo, E. L., Diez, M., and Santofimia, E.: Physicochemical gradients and meromictic stratification in Cueva de la Mora and other acidic pit lakes of the Iberian Pyrite Belt, Mine. Water Environment, 1-15, doi:10.1007/s10230-008-0059z, 2009.

Hamblin, P. F., Stevens C. L., and Lawrence, G. A.: Simulation of vertical transport in a mining pit lake, J. Hydraul. Eng-ASCE, 125(10), 1029-1038, 1999.

Hoare, R. A.: Problems of heat transfer in lake Vanda, a densitiy stratified antarctic lake, Nature, 210, 787-789, 1966.

Kelley, D. E.: Effective Diffusivities Within Oceanic Thermohaline Staircases, J. Geophys. Res., 89, 10484-10488, 1984.

Kelley, D. E., Fernando, H. J. S., Gargett, A. E., Tanny, J., and Özsoy, E.: The diffusive regime of double-diffusive convection, Prog. Oceanogr., 56, 461-481, doi:10.1016/S00796611(03)00026-0, 2003. 
Newman, F. C.: Temperature Steps in Lake Kivu: A Bottom Heated Saline Lake, J. Phys. Oceanogr., 6, 157-163, 1976.

Sánchez, X. and Roget, E.: Microstructure measurements and heat flux calculations of a triple-diffusive process in a lake within the diffusive layer convection regime, J. Geophys. Res., 112, C02012, doi:10.1029/2006JC003750, 2007.

Schmid, M., Lorke, A., Dinkel, C., Tanyileke, G., and Wüest, A.: Double-diffusive convection in Lake Nyos, Cameroon, DeepSea. Res. Pt. I, 51, 1097-1111, 2004.

Schmitt, R. W.: Double Diffusion in Oceanography, Annu. Rev. Fluid. Mech., 26, 255-285, 1994.

Stevens, C. L. and Lawrence, G. A.: Stability and meromixis in a water-filled mine pit, Limnol. Oceanogr., 43, 9746-9954, 1998.
Turner, J. S.: Buoyancy effects in fluids, Cambridge Monographs on Mechanics and Applied Mathematics, edited by: Batchelor, G. K., and Miles, J. W., Cambridge University Press, Cambridge, 370 pp., 1973.

von Rohden, C., Ilmberger, J., and Boehrer, B.: Assessing groundwater coupling and vertical exchange in a meromictic mining lake with an $\mathrm{SF}_{6}$-tracer experiment, J. Hydrol., 372, 102-108, 2009.

Wüest, A., Aeschbach-Hertig, W., Baur, H., Hofer, M., Kipfer, R., and Schurter, M.: Density structure and tritium-helium age of deep hypolimnetic water in the northern basin of Lake Lugano, Aquat. Sci., 54, 205-218, 1992. 